\title{
DNA, histones and neutrophil extracellular traps exert anti-fibrinolytic effects in a plasma environment ${ }^{1}$
}

Imre Varjúa, Colin Longstaff ${ }^{b}$, László Szabóc ${ }^{c}$ Ádám Zoltán Farkasa ${ }^{a}$, Veronika Judit Varga-Szabóa, Anna Tanka-Salamon ${ }^{\mathrm{a}}$, Raymund Machovicha, Krasimir Kolev ${ }^{\mathrm{a}}$

${ }^{a}$ Department of Medical Biochemistry, Semmelweis University, 1094 Budapest, Tüzoltó utca 37-47., Hungary

${ }^{b}$ Biotherapeutics Division, Haemostasis Section, National Institute for Biological Standards and Control, South Mimms, Herts, EN6 3QG UK

${ }^{c}$ Department of Functional and Structural Materials, Institute of Materials and Environmental Chemistry, Research Centre for Natural Sciences, Hungarian Academy of Sciences, 1117 Budapest, Magyar Tudósok körútja 2

Correspondence: Krasimir Kolev, Semmelweis University, Department of Medical Biochemistry, 1094 Budapest, Tüzoltó utca 37-47., Hungary, tel.: +36 1 4591500/60035, fax: +36 1 2670031, email: Krasimir.Kolev@eok.sote.hu

Short title: NETs inhibit plasma clot lysis

Word count: 4882

This article is not an exact copy of the original published article in Thrombosis and haemostasis. The definitive publisher-authenticated version of Thromb Haemost. 2015;113(6):1289-98. doi:

10.1160/TH14-08-0669 is available online at:

https://th.schattauer.de/en/contents/archive/issue/2217/manuscript/24160.html

\footnotetext{
${ }^{1}$ This work was supported by the Hungarian Scientific Research Fund OTKA 83023 and 112612.
} 


\section{SUMMARY}

In response to various inflammatory stimuli, neutrophils secrete neutrophil extracellular traps (NETs), web-like meshworks of DNA, histones and granular components forming supplementary scaffolds in venous and arterial thrombi. Isolated DNA and histones are known to promote thrombus formation and render fibrin clots more resistant to mechanical forces and tissue-type plasminogen activator (tPA)induced enzymatic digestion. The present study extends these earlier observations to a physiologically more relevant environment including plasma clots and NET-forming neutrophils. A range of techniques was employed including imaging (scanning electron microscopy (SEM), confocal laser microscopy, and photoscanning of macroscopic lysis fronts), clot permeability measurements, turbidimetric lysis and enzyme inactivation assays. Addition of DNA and histones increased the median fiber diameter of plasma clots formed with $16 \mathrm{nM}$ thrombin from 108 to 121 and $119 \mathrm{~nm}$, respectively, and decreased their permeability constant from 6.4 to 3.1 and $3.7 \times 10^{-9} \mathrm{~cm}^{2}$. Histones effectively protected thrombin from antithrombin-induced inactivation, while DNA inhibited plasminogen activation on the surface of plasma clots and their plasmin-induced resolution by 20 and $40 \%$, respectively. DNA and histones, as well as NETs secreted by phorbol-myristate-acetate-activated neutrophils, slowed down the tPA-driven lysis of plasma clots and the latter effect could be reversed by the addition of DNase (streptodornase). SEM images taken after complete digestion of fibrin in NET-containing plasma clots evidenced retained NET scaffold that was absent in DNase-treated clots. Our results show that DNA and histones alter the fibrin architecture in plasma clots, while NETs contribute to a decreased lytic susceptibility that can be overcome by DNase.

KEYWORDS: neutrophil extracellular traps, DNA, histones, fibrinolysis, plasmin

\section{Extra table}

What is known on this topic:
- In response to inflammatory stimuli neutrophils are able to expel their granular and
nuclear components to form NETs that capture a variety of microbes.
- NETs also entrap and activate platelets, and promote both pathways of the
coagulation cascade, contributing to an increased risk of venous and arterial
thrombosis.
- Isolated DNA and histones render fibrin clots more resistant to mechanical forces
and tPA-induced enzymatic degradation.
What this paper adds:
DNA and histones increase the fiber thickness and decrease the permeability of
fibrin in plasma clots.
- DNA alone inhibits plasmin-driven lysis of plasma clots.
- Clots formed by activated neutrophils hinder the tPA-induced resolution of plasma
Provides a rationale for NET-targeted strategies to improve thrombolysis.




\section{INTRODUCTION}

Neutrophil extracellular traps (NETs) composed of DNA, histones and other associated proteins secreted from activated neutrophils represent an evolutionarily conserved means of antimicrobial defence (1). Nevertheless, besides their protectiveness at the site of infection, NETs have been identified as key factors in the pathogenesis of numerous diseases (reviewed in (2)), including venous (reviewed in (3)) and arterial (4) thrombosis. In the course of NETosis (5), DNA and histones -the major components of NETs- are released from activated neutrophils together with other proteins (e.g. neutrophil elastase), creating web-like structures (1) capable of trapping not only various microbes, but also blood cells, platelets and proteins involved in coagulation. Histones, the most abundant proteins in NETs (6), exert clear pro-thrombotic effects by influencing cellular and protein components of the haemostatic system. They induce activation of platelets (7) and endothelial cells (8), inhibit activated protein C-mediated negative feedback of the coagulation cascade (9), and directly support thrombin activation (10). DNA, on the other hand, enhances the activity of factor XII (11), while neutrophil elastase and other proteases degrade inhibitors of the coagulation cascade (reviewed in (12)).

Considering this range of effects, and the fact that NETs are recognized as a supplementary scaffold of thrombi (besides fibrin) (13), the need for a thorough assessment of their influence on thrombolysis seems compelling. Our previous studies indicate that DNA and histones exert marked effects on the structural and mechanical parameters of fibrin clots, and render them more resistant to tissue-type plasminogen activator (tPA)-driven lysis (14). However, these investigations need to be extended to a plasma environment and explored using neutrophil-derived NETs.

\section{MATERIALS AND METHODS}

\section{Proteins and reagents}

Calf thymus DNA, streptokinase and fibrinogen (plasminogen-depleted) were from Calbiochem, LaJolla, CA, USA. Plasmin was generated using plasminogen (isolated from human plasma (15)) activated by streptokinase at $172 \mathrm{IU} / \mathrm{mg}$ zymogen. For plasmin inactivation assays, $40 \mu \mathrm{M}$ plasminogen was activated by $70 \mathrm{nM}$ tPA (Boehringer Ingelheim, Ingelheim am Rhein, Germany) at $37{ }^{\circ} \mathrm{C}$ for 25 min. Plasmin concentrations were calculated as described in (16). HIIIS (histone IIIS from calf thymus), PMA (phorbol 12-myristate 13-acetate), BSA (bovine serum albumin), HSA (human serum albumin) and mouse anti-human H3 antibody (SAB4200591) were obtained from Sigma-Aldrich, Budapest, Hungary. Thrombin (Serva Electrophoresis $\mathrm{GmbH}$, Heidelberg, Germany) was purified as described in (17). Antithrombin and Spectrozyme-PL (H-D-norleucyl-hexahydrotyrosyl-lysine-p-nitroanilide) were purchased from American Diagnostica, Pfungstadt, Germany. S-2251 (val-leu-lys- $p$-nitroanilide) was from Chromogenix SpA, Milano, Italy. Heparin was acquired from Wockhardt, Wrexham, UK. Activated protein C (APC, Xigris) was from Eli Lilley Inc, Indianapolis, USA. Streptodornase (08/230 the WHO 2nd International Standard for Streptodornase, a mixture of streptokinase and streptodornase) and $\alpha_{1}$-protease inhibitor (NIBSC preparation code 05/150) were obtained from NIBSC, South Mimms, UK. $\alpha_{2}$-plasmin inhibitor was purchased from Calbiochem. Alexa Fluor ${ }^{\circledR}$ 546-conjugated fibrinogen and goat anti-mouse antibody, Alexa Fluor ${ }^{\circledR} 488$-conjugated goat anti-rabbit antibody and fluorescent nucleic acid dye (TOTO-3 $($ ) were from Invitrogen Life Technologies, Budapest, Hungary. Rabbit antihuman citrullinated H3 (ab5103) was purchased from Abcam (Cambridge, UK). tPA was modified to express a C-terminal fusion of Yellow Fluorescent Protein (YFP) using pFastBac-tPA (and derivatives) as previously described (18). Citrated, fresh frozen plasma (fibrinogen concentration: $4.16 \mathrm{~g} / \mathrm{l}$ ) and buffy coat fraction of human blood were obtained from the Hungarian Blood Supply Service, Budapest, Hungary. If not otherwise indicated, plasma was recalcified with $12.5 \mathrm{mM} \mathrm{CaCl}{ }_{2}$ immediately before measurements. Isolation of neutrophil granulocytes from buffy coat and extraction of DNA were carried out as described in $(14,19)$. Neutrophil DNA was used for confocal studies; other assays were carried out using calf thymus DNA. If not otherwise indicated, experiments were performed using HEPES buffered saline (HBS: $10 \mathrm{mM}$ HEPES buffer $\mathrm{pH} 7.4$ containing $150 \mathrm{mM} \mathrm{NaCl}$ ) \pm additives. 
Plasma clots were prepared from mixtures of 2-fold diluted recalcified human plasma, and various concentrations of DNA and/or HIIIS and clotted with $16 \mathrm{nM}$ thrombin at $37^{\circ} \mathrm{C}$ for $60 \mathrm{~min}$. Clots were washed 7 times with distilled water at $4{ }^{\circ} \mathrm{C}$ for $5 \mathrm{~min}$.

Granulocytes at $5 \times 10^{4} / \mu \mathrm{l}$ (in $600 \mu \mathrm{l}$ phosphate-buffered saline $\mathrm{pH} 7.4$, PBS: $8.1 \mathrm{mM} \mathrm{Na}_{2} \mathrm{HPO}_{4}, 1.5 \mathrm{mM}$ $\mathrm{KH}_{2} \mathrm{PO}_{4}, 137 \mathrm{mM} \mathrm{NaCl}, 2.7 \mathrm{mM} \mathrm{KCl}$ and $5 \mathrm{mM}$ glucose) were pipetted into culture plate wells containing cover slips with a diameter of $6 \mathrm{~mm}$ at the bottom. Cells were activated with 50-100 nM PMA for 4 hours at $37^{\circ} \mathrm{C}$. After the incubation, the fluid phase was withdrawn. In certain cases, cover slips were thereafter dipped in a mixture of $10 \mathrm{nM}$ thrombin and $6 \mu \mathrm{M}$ fibrinogen.

For SEM imaging, samples were treated and examined with scanning electron microscope EVO40 (Carl Zeiss $\mathrm{GmbH}$, Oberkochen, Germany) and the images were analyzed to determine the diameter of the fibrin fibers as described previously $(14,20)$.

For LSM examination, samples were fixed and immunostained according to a protocol modified from (21), using anti-citrullinated $\mathrm{H} 3$ and anti-H3 antibodies, and fluorescent nucleic acid dye TOTO-3®. Confocal fluorescent images were taken using a Zeiss LSM710 confocal laser scanning microscope (Carl Zeiss, Jena, Germany).

\section{Clot permeability assays}

Fibrinogen at $8 \mu \mathrm{M}$ or plasma supplemented with $20 \mathrm{mM} \mathrm{CaCl}_{2} \pm$ additives $(50 \mu \mathrm{g} / \mathrm{ml} \mathrm{DNA}$ and/or 250 $\mu \mathrm{g} / \mathrm{ml} \mathrm{HIIIS)}$ were clotted with $16 \mathrm{nM}$ thrombin in plastic pipette tips. After $70 \mathrm{~min}$ of incubation at $37^{\circ} \mathrm{C}$, HBS was permeated through the clots. Pressure was kept constant by maintaining a fixed head volume.

$K_{S}$ (permeability coefficient) was calculated from the equation $K_{S}=\frac{Q \cdot L \cdot \eta}{t \cdot A \cdot \Delta P}(22)$, where $\mathrm{Q}=$ permeated volume of buffer $\left(\mathrm{cm}^{3}\right) ; \eta=$ viscosity of buffer $\left(10^{-2}\right.$ poise $\left.=10^{-7} \mathrm{~N} \mathrm{~s} \mathrm{~cm}^{-2}\right) ; \mathrm{L}=$ clot length $(1.5 \mathrm{~cm}$ for fibrin clots, $1.7 \mathrm{~cm}$ for plasma clots); $\mathrm{A}=$ average cross-sectional area of the clot $\left(0.102 \mathrm{~cm}^{2}\right.$ for fibrin clots, $0.057 \mathrm{~cm}^{2}$ for plasma clots); $\mathrm{t}=$ time $(\mathrm{s}) ; \Delta \mathrm{P}=$ pressure drop $\left(0.209 \mathrm{~N} \mathrm{~cm}^{-2}\right.$ for fibrin clots, 0.056 $\mathrm{N} \mathrm{cm}^{-2}$ for plasma clots).

\section{Thrombin inactivation assays}

Mixtures of antithrombin, thrombin and various concentrations of HIIIS and DNA in the presence or absence of heparin were incubated at room temperature. After various incubation times, clotting was initiated by the addition of fibrinogen. Clotting time was measured with a coagulometer $\mathrm{KC}-1 \mathrm{~A}$ (Amelung, Lemgo, Germany) at $37^{\circ} \mathrm{C}$.

\section{Plasminogen activation assay}

In 96-well microtiter plates, 2 -fold diluted recalcified plasma \pm additives $(50 \mu \mathrm{g} / \mathrm{ml}$ DNA and/or 250 $\mu \mathrm{g} / \mathrm{ml}$ HIIIS) was clotted with $16 \mathrm{nM}$ thrombin in a volume of $80 \mu \mathrm{l}$. After $45 \mathrm{~min}$ at $37^{\circ} \mathrm{C} 60 \mu \mathrm{l}$ of $28 \mathrm{nM}$ tPA and $0.6 \mathrm{mM}$ Spectrozyme-PL were placed on the surface of the clot. The forming plasmin generated $p$-nitroaniline, the absorbance of which was continuously recorded at $405 \mathrm{~nm}\left(\mathrm{~A}_{405}\right)$ with Zenith 200rt spectrophotometer (Anthos Labtec Instruments GmbH, Salzburg, Austria). The apparent maximal initial rate of plasminogen activation in the reactive layer of fibrin $\left(V_{a p p}\right)$ was calculated from $\mathrm{A}_{405}$ values as described in (23).

\section{Fibrinolytic assays}

tPA-driven lysis of plasma clots was studied in 96-well microtiter plates. Two-fold diluted recalcified plasma was mixed with $16 \mathrm{nM}$ thrombin, $3.75 \mu \mathrm{M}$ plasminogen, and various concentrations of DNA and HIIIS. In another set of experiments, instead of pure DNA and histones, $5 \times 10^{3} / \mu 1$ granulocytes (in 
HBS containing $5 \mathrm{mM}$ glucose) $\pm 100 \mathrm{nM}$ PMA were incorporated into two-fold diluted recalcified plasma isolated from buffy coat containing $3.75 \mu \mathrm{M}$ plasminogen. Following 60 min clotting, lysis was initiated by addition of $200 \mathrm{nM}$ tPA to the clot surface. In the case of experiments with neutrophils, the time for clotting was prolonged up to 240 min to allow for NET formation, and tPA was supplemented with various concentrations of APC, streptokinase, and streptodornase to initiate lysis. Clot formation and dissolution was followed by measuring the light absorbance at $340 \mathrm{~nm}$ at $37^{\circ} \mathrm{C}$ with a Zenyth $200 \mathrm{rt}$ microplate spectrophotometer. For adequate comparison of lytic rates from measurements, in which different maximum turbidity values were reached despite the identical quantities of fibrin, the absorbance values were normalized as $\left(A-A_{0}\right) / A_{\max }$ where $A_{\max }$ is the maximal- and $A_{0}$ is the final absorbance at $340 \mathrm{~nm}$ after complete lysis. The time needed to reduce the turbidity of the clot to a given fraction of the maximal value (T0.5 to reach $0.5 A_{\max }$, T0.1 to reach $0.1 A_{\max }$ ) was used as a quantitative parameter of fibrinolytic activity.

For LSM imaging of lysis, clots were prepared from 2-fold diluted recalcified plasma supplemented with $90 \mathrm{nM}$ Alexa Fluor ${ }^{\circledR}$ 546-conjugated fibrinogen and $1.5 \mu \mathrm{M}$ plasminogen, clotted with $16 \mathrm{nM}$ thrombin for $30 \mathrm{~min}$ at room temperature in sterile, uncoated IBIDI VI $0.4 \mu$-slides (Ibidi GmbH, Martinsried, Germany). In certain cases, $45 \mu \mathrm{g} / \mathrm{ml}$ DNA and $/$ or $280 \mu \mathrm{g} / \mathrm{ml}$ HIIIS were also present in the mixture. Thereafter, $85 \mathrm{nM}$ tPA-YFP (supplemented with $3 \mu \mathrm{M}$ plasminogen) was added to the edge of the clot and the fluorescence was monitored as described in (23).

Plasmin-induced lysis was also examined in IBIDI VI $0.4 \mu$-slides. Two-fold diluted recalcified plasma containing 0/50 $\mu \mathrm{g} / \mathrm{ml}$ DNA and/or $250 \mu \mathrm{g} / \mathrm{ml}$ HIIIS were mixed with $16 \mathrm{nM}$ thrombin. The mixtures were quickly pipetted into the $30 \mu \mathrm{l}$ channnels of IBIDI slides, and incubated at $37^{\circ} \mathrm{C}$ for $30 \mathrm{~min}$. Lysis was initiated by the addition of $60 \mu \mathrm{l}$ of $5 \mu \mathrm{M}$ plasmin introduced to the opening of the channels and followed by time lapse photoscanning of the transparent fluid/opaque clot boundary.

\section{Plasmin inactivation assays}

The effects of DNA \pm histones on the interactions of isolated plasma inhibitors and plasmin were evaluated at $37^{\circ} \mathrm{C}$ by following slow binding inhibition kinetics of $0.2 \mathrm{nM}$ plasmin with a range of $\alpha_{2}-$ plasmin inhibitor concentrations in HBS containing $1 \mathrm{mg} / \mathrm{ml}$ fibrinogen and $500 \mu \mathrm{M}$ tranexamic acid to mimic fibrin and slow down kinetics of plasmin- $\alpha_{2}$-plasmin inhibitor complex formation (24). Similarly, slow binding inhibition of $0.4 \mathrm{nM}$ plasmin by a range of $\alpha_{1}$-protease inhibitor concentrations was studied in HBS containing $1 \mathrm{mg} / \mathrm{ml}$ HSA. Plasmin activity was monitored by following the hydrolysis of $0.3 \mathrm{mM} \mathrm{S}-2251$. Kinetics were studied for up to 2.5 hours in the presence of no further additives or with $50 \mu \mathrm{g} / \mathrm{ml}$ of DNA or HIIIS. Association rate constants were calculated from plots of $\mathrm{k}_{\mathrm{obs}}$ versus inhibitor concentrations, after fitting to the equation for irreversible binding of plasmin and inhibitor $\left(\alpha_{2}\right.$-plasmin inhibitor or $\alpha_{1}$-protease inhibitor), $A_{405}=A_{0}+\left(v_{0} / k_{o b s}\right)\left(1-\exp \left(-k_{o b s} t\right)\right.$, where $A_{o}$ is initial absorbance, $\mathrm{k}_{\mathrm{obs}}$ is the apparent rate constant for complex formation and $\mathrm{v}_{\mathrm{o}}$ is the initial rate of plasmin activity on S-2251 (24). To study the effect of DNA on antithrombin-plasmin interaction, 2.5 $\mathrm{nM}$ plasmin and $0.7 \mu \mathrm{M}$ antithrombin in HBS containing $1 \mathrm{mg} / \mathrm{ml}$ BSA were mixed with a range of DNA concentrations, and plasmin activity was monitored by following the hydrolysis of $0.05 \mathrm{mM}$ Spectrozyme-PL.

\section{Statistical analysis}

The distribution of the data on fiber diameter was analyzed using an algorithm described previously: theoretical distributions were fitted to the empirical data sets and compared using Kuiper's test and Monte Carlo simulation procedures running under the Matlab 8.1.0.604 (R2013a) (The Mathworks, Natick, MA) $(17,20)$. The statistical evaluation of other experimental measurements in this report was performed with Kolmogorov-Smirnov test (Statistical Toolbox 7.3 of Matlab). 


\section{RESULTS}

\section{Structural studies}

If isolated neutrophils were activated for $4 \mathrm{~h}$ by PMA, well-defined NET structures could be observed with SEM (Fig. 1A and 1B) as a meshwork of fine fibers (approximately $10 \mathrm{~nm}$ diameter) decorated with protein aggregates and cell debris. LSM analysis confirmed the presence of the NETosis-hallmark citrullinated histones (25) in the nucleus of the activated neutrophils, as well as in the extracellular space of immunostained samples (Fig. 1E). If NET formation was induced in a fibrin environment, fibrin fibers were around $100 \mathrm{~nm}$ in diameter and could be clearly identified in fibrin-rich regions of SEM images (Fig. 1C and D), however, in heterogeneous regions of the clot, the distinction between NET and fibrin was not always straightforward. For reliable quantitative analysis of the fibrin fiber diameter, this meshwork was modelled in a simplified, more homogeneous experimental setup. DNA and/or HIIIS were added to recalcified plasma clotted with thrombin at concentrations matching the values used for lysis $(16 \mathrm{nM})$ and thrombin inactivation assays $(60 \mathrm{nM})$. Addition of DNA, HIIIS or their mixture resulted in thicker fibers at $16 \mathrm{nM}$ thrombin, while at the higher thrombin concentration HIIIS caused a slight, although statistically significant reduction of fiber diameter. DNA alone had similar effects in the two systems, leading to formation of thicker fibers (Table 1).

Since thrombin concentration is a major determinant of fiber thickness (18), plasma inhibitors affecting thrombin activity might play a role in the observed changes in fibrin structure. To test this possibility, the influence of histones/DNA on the inactivation of thrombin was studied by detecting residual thrombin activity after exposure to its main plasma inhibitor antithrombin. HIIIS proved to be very effective in protecting thrombin from inactivation regardless of the presence of heparin. Increasing concentrations of DNA partially attenuated histone-mediated protection of thrombin in the presence of physiological antithrombin concentration $(2.5 \mu \mathrm{M})$ (Suppl. Fig. 1S).

Fiber diameter values provide indirect information about the average pore size of the fibrin network (thicker fibers are associated with larger pores) $(26,27)$, which can be validated by measurement of clot permeability, a physiologically more relevant indicator of pore size (28). As Table 2 shows, HIIIS reduced the permeability constant in plasma clots by almost $50 \%$, while it increased permeability approximately 4 -fold in fibrin clots, which could be partially opposed by the addition of DNA. DNA alone reduced the permeability constant in both fibrin and plasma clots by 27 and $51 \%$, respectively.

\section{tPA-dependent plasminogen activation and lysis of plasma clots containing DNA and HIIIS}

In view of the known impact of fibrin structure on its lytic susceptibility (reviewed in 29) DNA and HIIIS could be expected to affect the sequential steps of fibrinolysis (plasminogen activation, clot digestion). To assess their effects on plasminogen activation, DNA and HIIIS were incorporated into plasma clots and a chromogenic plasmin substrate (Spectrozyme-PL) was added to the clot surface together with IPA (Fig. 2). While DNA alone reduced the rate of plasmin formation by $20 \%$, histones enhanced plasmin generation, independently of the presence of DNA (Fig. 2, inset).

To study the effects of DNA and HIIIS on plasmin-induced lysis, plasma clots were prepared in microchannels and lysis was followed by time-lapse photoscanning of the lytic front. Incorporation of DNA in the clots reduced the distance run by the lysis front at $60 \mathrm{~min}$ by $40 \%$. HIIIS alone had no significant effect, while it opposed DNA effects when added in combination (Fig. 3). A possible explanation for the effect of DNA in this assay might be the DNA-mediated enhancement of plasmin inactivation. This was tested by measurements of plasmin interactions with physiologically relevant antiproteases ( $\alpha_{2}$-plasmin inhibitor, $\alpha_{1}$-protease inhibitor, antithrombin). Neither DNA nor HIIIS had significant effect on the apparent rate constants of plasmin inactivation by the tested inhibitors (Suppl. Fig. 2S and 3S).

The microscale pattern of tPA-induced plasma clot lysis was examined with LSM. Plasma clots were supplemented with fluorescent fibrinogen, and the movement of the lysis front with accumulated fluorescent tPA-YFP was measured for $30 \mathrm{~min}$ (Fig. 4). DNA and histones alone had non-significant effects on the tPA-front penetration, however, when added simultaneously, the final run distance of the lysis front was reduced by approximately $25 \%$. Hindered lysis was accompanied by subtle changes in the microscopic pattern of the clot-tPA interface: unlike the rough granular surface seen in clots without 
any additives, a fine granular structure showing less aggregate formation could be observed in clots formed in the presence of DNA and HIIIS (Fig. 4A and D). Delayed lysis was also observed in the final stages of the turbidimetric assay of plasma clots containing DNA and HIIIS (Fig. 5). Closer analysis of lysis curves revealed that DNA and histones prolonged the average time elapsed until $90 \%$ clot lysis (T0.1) when added separately or together, while the time needed for 50\% lysis (T0.5) remained largely unchanged (Fig. 5, inset).

\section{Lysis of plasma clots containing activated neutrophils}

PMA-activated neutrophils incorporated within plasma clots may be a better approach to the in vivo situation and their effects on clot lysis were studied in another set of turbidimetric assays. The presence of NETs generated by granulocytes at physiological cell count incorporated in the clots increased T0.1 values by a factor of $2.11 \pm 0.23$ ( $\mathrm{n}=14$ from 3 independent experiments, $\mathrm{p}<0.05$ ), while T0.5 was only moderately increased by a factor of $1.25 \pm 0.26$ ( $\mathrm{n}=14$ from 3 independent experiments, $\mathrm{p}<0.05$ ) (Suppl. Fig. 4S). To investigate which NET components were responsible for the delayed lysis, tPA was supplemented with enzymes capable of DNA or histone degradation. Streptococci produce a DNase (streptodornase) in addition to the plasminogen activator protein streptokinase, while APC is known to digest histones (30). Streptodornase was able to enhance the lytic potency of streptokinase in plasma clots containing NET-producing neutrophils (Fig. 6 and Table 3), while in cell-free plasma clots this effect was absent (data not shown). Addition of APC to the fibrinolysis cocktail had no significant effect. Macroscopic inspection of clot remnants after 200 min lysis showed remarkable differences: while most wells contained a fine, web-like aggregate that remained unlysed, these were absent from the wells containing streptodornase (Fig. 6, inset). SEM images of aggregates revealed intact NET structures retained after the complete digestion of fibrin by plasmin (Fig. 6, inset).

\section{DISCUSSION}

Although the circulating cell-free DNA level is generally low in blood $(50-100 \mathrm{ng} / \mathrm{ml})(31)$, under certain pathological conditions (e.g. malignancy), this can rise up to $0.5-5 \mu \mathrm{g} / \mathrm{ml}$ (32), while studies in baboon sepsis models evidence circulating histone levels up to $70 \mu \mathrm{g} / \mathrm{ml}(30)$. In addition to these baseline values, thrombosis-associated inflammatory signals may induce migration of granulocytes into thrombi (33), where expulsion of nuclear contents through necrosis or NETosis could lead to higher local concentrations. The possibility for extreme focal accumulation of NET components is exemplified by the micromolar concentration of neutrophil elastase measured in the immediate pericellular zone of activated neutrophils (34), and it is supported by the intense DNA and histone staining observed in leukocyte-rich thrombi (14). Therefore, the range applied in this study $(5-50 \mu \mathrm{g} / \mathrm{ml}$ for DNA and 0.5$280 \mu \mathrm{g} / \mathrm{ml}$ for histones) seems relevant to reflect their availability following clot formation in an inflammatory environment.

Regardless of their sources -dead cells in the necrotic debris of eroded atherosclerotique plaques, or neutrophils forming NETs as a response to intravascular inflammatory signals- DNA and histones are most likely to appear as complexes in the circulation (35). Nevertheless, mounting data suggest that, under certain conditions, histones might become separated from DNA. Previous analysis has shown that less $\mathrm{H} 3$ and $\mathrm{H} 4$ histones are found in NETs than in chromatin (6), and that citrullination displaces $\mathrm{H} 1$ from chromatin in certain cells (36). In addition, our previous immunohistochemistry studies on ex vivo arterial thrombi reveal clot regions where DNA and histones are not co-localized (14). Taken together, these data provide a basis to assess the effect of isolated DNA and histones as well as NETs and other DNA-histone complexes on the structure and lysis of clots.

In our previous and present studies, DNA and HIIIS (from calf thymus) were used for that purpose, however, this imposes limitations on the in vivo extrapolation from the data obtained. For instance, citrullination of histones, which is a prominent hallmark of NETosis ((25) and Fig. 1E), may lead to alterations of their effects on clot structure and lysis. Therefore, we have expanded our studies with the incorporation of PMA-activated neutrophils into plasma clots to gain physiologically more relevant information on the fibrinolytic effects of NETs. 


\section{Effects of DNA and HIIIS on clot structure}

Clot structure, a major determinant of lytic susceptibility, is influenced by a variety of enzymatic (e.g. thrombin concentration) (18), cellular (e.g. red blood cells) (37) and mechanical (e.g. shear stress) (17) factors. According to our studies, DNA and histones further increase the already existing complexity.

In plasma clots formed with $16 \mathrm{nM}$ thrombin, the median fiber diameter increased in the presence of the examined additives, and the strongest effect was seen when DNA and histones were added in combination (Table 1). These results are in agreement with the tendencies observed in fibrin clots (14). Given that the apparent thrombin and fibrinogen concentrations were identical in the two systems (fibrin and plasma clots), this finding supports the notion that DNA and histones disrupt the spatial arrangement of monomer blocks and protofibrils, as suggested by small-angle X-ray scattering data (14). The essentially minor effect of histones in plasma clots formed with $60 \mathrm{nM}$ thrombin with a slight opposite, decreasing trend of diameter values, however, suggests that this is not the only mechanism through which histones influence fiber thickness. Thrombin inactivation assays (Suppl. Fig. 1S) revealed that histones are able to protect thrombin from inhibition by antithrombin (in agreement with (9), where histones were found to shorten clotting times in normal plasma), in support of the previous findings and adding a new mechanism emphasizing their procoagulant role (7-10). Given that increasing thrombin concentrations result in formation of thinner fibers in plasma clots (24), the final fibrin structure in the presence of histones may reflect the net result of two opposing tendencies (disruption of protofibril arrangement versus protection of thrombin from inactivation).

Fiber diameter and clot pore area are considered to be positively correlated $(26,27)$. Permeability coefficients measured in fibrin clots supported this correlation; in the present study we established that the previously reported increase in median fiber diameter (14) was accompanied by a higher value of the permeability constant implying larger average pore areas in clots containing histones \pm DNA (Table 2). However, DNA alone decreased permeability, despite the increased fiber diameters, which may be attributed to its pore-filling property suggested by Fig. $1 \mathrm{C}$. In the more complex plasma environment, the size of pores estimated from permeation studies did not strictly follow the trend predicted by fiber thickness (Tables 1 and 2). These discrepancies may point out the importance of interactions between DNA/histones and other components of plasma, which remain to be further investigated.

\section{Effects of DNA, HIIIS and NETs on clot lysis}

Fibrinolysis is a result of sequential activation of plasminogen and plasmin-catalyzed cleavage of fibrin fibers. On the surface of clots both steps are affected by the structural characteristics (e.g. fiber thickness and permeability) of fibrin, and in vivo this scenario can be further complicated by a variety of blood-borne factors (reviewed in (29)). With our experiments we modelled the fibrinolytic events relevant to therapeutic thrombolysis applying tPA concentrations that have been reported in plasma of patients treated for acute myocardial infarction $(150 \mathrm{nM})$ or deep vein thrombosis $(300 \mathrm{nM})(38,39)$.

The changes observed in clot structure in the presence of DNA and HIIIS were accompanied by alterations of clot lysis. According to LSM (Fig. 4), DNA and histones disturbed the pattern of tPAinduced lysis, and their combination resulted in a $25 \%$ decrease in the average run distance of tPA fronts (despite the enhanced velocity of plasmin formation on the clot surface shown in Fig. 2). These microscale data were in line with the turbidimetric assay, in which DNA and HIIIS prolonged T0.1 by approximately 15\% while T0.5 remained essentially unchanged (Fig. 5, inset). This is in good agreement with time lapse images of lysing fibrin clots containing DNA/histones showing that early fibrinolysis is unaffected but complete clot breakdown is delayed (14). Studies using isothermal titration calorimetry have previously shown interactions between isolated DNA/HIIIS and large FDPs (molecular weight $>150 \mathrm{kDa}$ ) (14) providing a rationale for the retardation of the late phase of clot lysis. When lysis was initiated with plasmin, histones \pm DNA had negligible effects on the macroscopic lytic front movement (Fig. 3), whereas DNA alone hindered lysis. Since in our assays DNA failed to potentiate inhibition of plasmin by its major plasma inhibitors (Suppl. Fig. 2S and 3S), its antifibrinolytic effect might be explained by blocking plasmin binding to fibrin as shown in (40), where double stranded DNA at $1-20 \mu \mathrm{g} / \mathrm{ml}$ inhibited plasmin-induced lysis of pure fibrin clots without substantially affecting the binding kinetics of plasmin to $\alpha_{2}$-plasmin inhibitor. In light of its inhibitory effects on both tPA- or plasmin-mediated lysis and the hindered tPA-induced plasminogen activation on 
the clot surface (Fig. 2), a definite anti-fibrinolytic role can be attributed to DNA in a plasma environment.

SEM and LSM confirmed that PMA-activated neutrophils produced NETs in our system (Fig. 1), and their incorporation in plasma clots resulted in a two-fold increase of T0.1 in comparison with clots containing non-activated cells. However, since the extent of lysis prolongation exceeds the effect seen with the combination of isolated DNA and histones, additional factors may also play a role in delayed fibrinolysis observed in this experimental setup. For example, peptidyl-arginyl-deiminase 4, the intracellular trigger of NET formation (25), has been shown to modify antithrombin and fibrinogen $(41,42)$ in addition to histones, with possible lytic consequences. Besides its procoagulant effects mentioned in the Introduction section, NET-bound neutrophil elastase could be expected to exert a profibrinolytic activity, due to (I) degradation of $\alpha_{2}$-plasmin inhibitor (43), (II) conversion of plasminogen to the more readily activatable miniplasminogen, and (III) its direct fibrinolytic activity (44). Accordingly, pure fibrin containing PMA-activated neutrophils spontaneously lysed within 3-4 h indicating the release of neutrophil elastase as a part of NET-formation (data not shown). However, in a plasma environment rich in antiproteases, the overall effect of NETs on lysis was inhibitory despite the presence of neutrophil elastase (Suppl. Fig. 4S), underlining the significance of DNA in lytic resistance.

\section{Clinical perspective}

Besides the administration of tPA in cardio- and cerebrovascular diseases $(45,46)$, direct plasmin application has been recently proposed as a safe thrombolytic method (47). Both strategies are targeting the fibrin meshwork, however, in vivo thrombi may contain NETs serving as supplementary scaffold (reviewed in 13), and histones/DNA may also accumulate in clots in a NETosis-independent manner (e.g. necrosis within atherosclerotic plaques). According to our current study, DNA alone hinders plasmin-mediated clot digestion, while DNA, histones, and NETs render plasma clots more resistant to lysis induced by therapeutic concentrations of tPA. APC, which digests histones in purified systems (30), failed to shorten lysis times in plasma clots containing NETs when combined with tPA (Table 3). This may be explained by reduced activity of APC on NET-bound histones (7), and that protease treatment leaves NET integrity intact. In contrast, addition of streptodornase -known to disrupt NETs (48)- accelerated clot degradation (Table 3), showing that NETs are also effectively degraded by the enzyme in a plasma clot environment (Fig. 6, inset).

Previous work examining lysis of whole blood clots (49), and our investigations carried out with fibrin clots (14) (both using DNase I), as well as our present studies using plasma clots and streptodornase suggest that more efficient thrombolysis might result from combinations of fibrinolytic agents and enzymes able to digest DNA. Additional advantage of such an approach stems from the finding that plasmin enhances the effectiveness of DNases (50) and evidence from nature that some streptococci have increased their pathogenicity by co-evolving the plasminogen activator, streptokinase, and a DNase, streptodornase, to overcome host defences. Nevertheless, in vivo lysis models are required to decide whether these findings can be translated into actual clinical benefits.

\section{ACKNOWLEDGEMENT}

The authors are grateful to Györgyi Oravecz, Krisztián Bálint and Judit Skopál for their help.

\section{Conflict of interest}

None to declare.

\section{REFERENCES}

1. Brinkmann V, Reichard U, Goosman C, et al. Neutrophil extracellular traps kill bacteria. Science 2004; 303: 1532-1535.

2. Branzk N, Papayannopoulos V. Molecular mechanisms regulating NETosis in infection and disease. Semin Immunopathol 2013; 35: 513-530. 
3. Borissoff JI, Ten Cate H. From neutrophil extracellular traps release to thrombosis: an overshooting host-defense mechanism?: Commentary. J Thromb Haemost 2011; 9: 17911794.

4. Darbousset R, Thomas GM, Mezouar S, et al. Tissue factor-positive neutrophils bind to injured endothelial wall and initiate thrombus formation. Blood 2012; 120: 2133-2143.

5. Fuchs TA, Abed U, Goosmann C, et al. Novel cell death program leads to neutrophil extracellular traps. J Cell Biol 2007; 176: 231-241.

6. Urban CF, Ermert D, Schmid M, et al. Neutrophil Extracellular Traps Contain Calprotectin, a Cytosolic Protein Complex Involved in Host Defense against Candida albicans. PLoS Pathog 2009; 5: e1000639.

7. Fuchs TA, Bhandari AA, Wagner DD. Histones induce rapid and profound thrombocytopenia in mice. Blood. 2011; 118: 3708-3714.

8. Saffarzadeh M, Juenemann C, Queisser MA, et al. Neutrophil extracellular traps directly induce epithelial and endothelial cell death: a predominant role of histones. PLoS One 2012; 7: e32366.

9. Ammollo CT, Semeraro F, Xu J, et al. Extracellular histones increase plasma thrombin generation by impairing thrombomodulin-dependent protein $\mathrm{C}$ activation. J Thromb Haemost 2011; 9: 1795-1803.

10. Barranco-Medina S, Pozzi N, Vogt AD, et al. Histone H4 Promotes Prothrombin Autoactivation. J Biol Chem 2013; 288: 35749-35757.

11. Von Bruhl M-L, Stark K, Steinhart A, et al. Monocytes, neutrophils, and platelets cooperate to initiate and propagate venous thrombosis in mice in vivo. J Exp Med 2012; 209: 819-835.

12. Brinkmann V, Zychlinsky A. Neutrophil extracellular traps: Is immunity the second function of chromatin? J Cell Biol 2012; 198: 773-783.

13. Martinod K, Wagner DD. Thrombosis: tangled up in NETs. Blood 2014; 123: 2768-2776.

14. Longstaff C, Varjú I, Sótonyi P, et al. Mechanical Stability and Fibrinolytic Resistance of Clots Containing Fibrin, DNA, and Histones. J Biol Chem 2013; 288: 6946-6956.

15. Deutsch D, Mertz E. Plasminogen: purification from human plasma by affinity chromatography. Science 1970; 170: 1095-1096.

16. Kolev K, Léránt I, Tenekejiev K, et al. Regulation of fibrinolytic activity of neutrophil leukocyte elastase, plasmin, and miniplasmin by plasma protease inhibitors. J Biol Chem 1994; 269: 17030-17034.

17. Varjú I, Sótonyi $\mathrm{P}$, Machovich R, et al. Hindered dissolution of fibrin formed under mechanical stress. J Thromb Haemost 2011; 9: 979-986.

18. Longstaff C, Thelwell C, Williams SC, et al. The interplay between tissue plasminogen activator domains and fibrin structures in the regulation of fibrinolysis: kinetic and microscopic studies. Blood 2011; 117: 661-668.

19. Wohner N, Keresztes Z, Sótonyi P, et al. Neutrophil granulocyte-dependent proteolysis enhances platelet adhesion to the arterial wall under high-shear flow. J Thromb Haemost 2010; 8: 1624-1631. 
20. Nikolova N, Toneva-Zheynova D, Kolev K, et al. Monte Carlo statistical tests for identity of theoretical and empirical distributions of experimental data. In: Theory and applications of Monte Carlo simulations. InTech 2013; pp. 1-26.

21. Brinkmann V, Laube B, Abu Abed U, et al. Neutrophil extracellular traps: how to generate and visualize them. J Vis Exp 2010; 36, e1724.

22. Woodhead JL, Nagaswami C, Matsuda M, et al. The ultrastructure of fibrinogen Caracas II molecules, fibers, and clots. J Biol Chem 1996; 271: 4946-4953.

23. Kovács A, Szabó L, Longstaff C, et al. Ambivalent roles of carboxypeptidase B in the lytic susceptibility of fibrin. Thromb Res 2014; 133: 80-87.

24. Longstaff C, Gaffney PJ. Serpin-serine protease binding kinetics: alpha2-antiplasmin as a model inhibitor. Biochemistry 1991; 30: 979-986.

25. Wang Y, Li M, Stadler $\mathrm{S}$, et al. Histone hypercitrullination mediates chromatin decondensation and neutrophil extracellular trap formation. J Cell Biol 2009; 184: 205-213.

26. Blombäck B, Carlsson K, Fatah K, et al. Fibrin in human plasma: gel architectures governed by rate and nature of fibrinogen activation. Thromb Res 1994; 75: 521-538.

27. Ferry JD, Morrison PR. Preparation and properties of serum and plasma proteins; the conversion of human fibrinogen to fibrin under various conditions. J Am Chem Soc 1947; 69: $388-400$.

28. Lord ST. Molecular Mechanisms Affecting Fibrin Structure and Stability. Arterioscler Thromb Vasc Biol 2011; 31: 494-499.

29. Weisel JW, Litvinov RI. The biochemical and physical process of fibrinolysis and effects of clot structure and stability on the lysis rate. Curr Med Chem-Cardiovasc Hematol Agents 2008; 6: 161-180.

30. Xu J, Zhang X, Pelayo R, et al. Extracellular histones are major mediators of death in sepsis. Nat Med 2009; 15: 1318-1321.

31. Steinman CR. Free DNA in serum and plasma from normal adults. J Clin Invest 1975; 56 : $512-515$.

32. Leon SA, Shapiro B, Sklaroff DM, et al. Free DNA in the serum of cancer patients and the effect of therapy. Cancer Res 1977; 37: 646-650.

33. Saha P, Humphries J, Modarai B, et al. Leukocytes and the Natural History of Deep Vein Thrombosis: Current Concepts and Future Directions. Arterioscler Thromb Vasc Biol. 2011; 31: 506-512.

34. Liou TG, Campbell EJ. Nonisotropic enzyme-inhibitor interactions: a novel nonoxidative mechanism for quantum proteolysis by human neutrophils. Biochemistry 1995; 34: 1617116177.

35. Esmon CT. Molecular circuits in thrombosis and inflammation. Thromb Haemost 2013; 109: 416-420.

36. Christophorou MA, Castelo-Branco G, Halley-Stott RP, et al. Citrullination regulates pluripotency and histone H1 binding to chromatin. Nature 2014; 507: 104-108. 
37. Wohner N, Sotonyi P, Machovich R, et al. Lytic Resistance of Fibrin Containing Red Blood Cells. Arterioscler Thromb Vasc Biol 2011; 31: 2306-2313.

38. Tebbe U, Tanswell P, Seifried E, et al. Single-bolus injection of recombinant tissue-type plasminogen activator in acute myocardial infarction. Am J Cardiol 1989; 64: 448-453.

39. Geier B, Grossefeld M, Barbera L, et al. Pharmacokinetics of tissue plasminogen activator in an isolated extracorporeal circuit. J Vasc Surg 2001; 33: 165-169.

40. Komissarov AA, Florova G, Idell S. Effects of extracellular DNA on plasminogen activation and fibrinolysis. J Biol Chem 2011; 286: 41949-41962.

41. Chang X, Yamada R, Sawada T, et al. The inhibition of antithrombin by peptidylarginine deiminase 4 may contribute to pathogenesis of rheumatoid arthritis. Rheumatology 2005; 44: 293-298.

42. Masson-Bessière C, Sebbag M, Girbal-Neuhauser E, et al. The major synovial targets of the rheumatoid arthritis-specific antifilaggrin autoantibodies are deiminated forms of the $\alpha$-and $\beta$ chains of fibrin. J Immunol 2001; 166: 4177-4184.

43. Machovich R, Owen WG. An elastase-dependent pathway of plasminogen activation. Biochemistry 1989; 28: 4517-4522.

44. Kolev K, Tenekedjiev K, Komorowicz E, et al. Functional evaluation of the structural features of proteases and their substrate in fibrin surface degradation. J Biol Chem 1997; 272: 13666 13675.

45. Armstrong PW, Gershlick AH, Goldstein P, et al. Fibrinolysis or Primary PCI in ST-Segment Elevation Myocardial Infarction. N Engl J Med 2013; 368: 1379-1387.

46. Adams HP, del Zoppo G, Alberts MJ, et al. Guidelines for the Early Management of Adults With Ischemic Stroke: A Guideline From the American Heart Association/American Stroke Association Stroke Council, Clinical Cardiology Council, Cardiovascular Radiology and Intervention Council, and the Atherosclerotic Peripheral Vascular Disease and Quality of Care Outcomes in Research Interdisciplinary Working Groups: The American Academy of Neurology affirms the value of this guideline as an educational tool for neurologists. Circulation 2007; 115: e478-e534.

47. Marder VJ. Historical perspective and future direction of thrombolysis research: the rediscovery of plasmin: The re-discovery of plasmin. J Thromb Haemost 2011; 9: 364-373.

48. Buchanan JT, Simpson AJ, Aziz RK, et al. DNase expression allows the pathogen group A Streptococcus to escape killing in neutrophil extracellular traps. Curr Biol 2006; 16: 396-400.

49. Fuchs TA, Brill A, Duerschmied D, et al. Extracellular DNA traps promote thrombosis. Proc Natl Acad Sci U S A 2010; 107: 15880-15885.

50. Napirei M, Wulf S, Mannherz HG. Chromatin breakdown during necrosis by serum Dnase 1 and the plasminogen system. Arthritis Rheum. 2004; 50: 1873-1883. 


\section{FIGURE LEGENDS}

Fig. 1 SEM and LSM images of NETs produced by PMA-activated neutrophil granulocytes. AB: Web-like structures entrapping cells and cell-derived debris following $4 \mathrm{~h}$ activation of isolated neutrophil leukocytes by $50 \mathrm{nM}$ PMA. C-D: NETs in a fibrin-rich environment (following PMA activation neutrophils were coated with a mixture of $10 \mathrm{nM}$ thrombin and $6 \mu \mathrm{M}$ fibrinogen). The thicker, coarse fibrin $(\mathrm{C}$ : in the foreground, D: to the right) merges with the fine structure of NETs (C: in the background, partially filling the pores of fibrin, D: left bottom corner). Scale bar=1 $\mu \mathrm{m}$ (A-D). E: LSM image of neutrophils activated in the same way as in panel A. The extracellular regions show DNA staining colocalized with citrullinated (citH3) and/or unmodified histone H3 (H3). Citrullination is also visible intracellularly. Scale bar $=20 \mu \mathrm{m}$.

Fig. 2 tPA-induced plasminogen activation on the clot surface. Plasma clots containing plasminogen and the indicated additives were prepared and thereafter IPA and the plasmin substrate Spectrozyme-PL were added. The absorbance of the liberated $p$-nitroaniline was continuously measured at $405 \mathrm{~nm}\left(\mathrm{~A}_{405}\right)$, and plotted against time squared. The figure shows mean values of eight measurements from a representative experiment. Inset: apparent maximal activation rates $\left(V_{a p p}\right)$ were calculated using the equation $\Delta A_{405}=0.5 \varepsilon k_{1} V_{a p p} t^{2}$, where $\varepsilon$ is the extinction coefficient of p-nitroaniline, $k_{l}$ is the turn-over number of plasmin on Spectrozyme-PL, $k_{c a t}$ and $[t P A]$ are the catalytic constant for plasminogen activation and the concentration of tPA in the reactive layer on the surface of fibrin, respectively. The term $V_{a p p}=k_{c a t}[t P A]$ is equivalent to the apparent maximal rate of plasminogen activation in the reactive layer of fibrin and was determined from linear regression according to the above mentioned equation (23). Mean values and standard deviation presented here are calculated from mean values of 3 independent experiments with 6-8 replicates each. Asterisk indicates a difference significant at $\mathrm{p}<0.05$ in comparison to control.

Fig. 3 Plasmin-induced lysis of clots. Two-fold diluted recalcified plasma mixed with $16 \mathrm{nM}$ thrombin, and additives was injected in $0.4 \mathrm{~mm}$ high channels of microslides (IBIDITM) through the upper orifice, and $5 \mu \mathrm{M}$ plasmin was applied through the lower orifice after $60 \mathrm{~min}$ of clotting. A: initial stage. B: lysis fronts in the same microslide after $60 \mathrm{~min}$. Additives (from left to right): none, 50 $\mu \mathrm{g} / \mathrm{ml}$ DNA, $250 \mu \mathrm{g} / \mathrm{ml}$ HIIIS, $50 \mu \mathrm{g} / \mathrm{ml}$ DNA $+250 \mu \mathrm{g} / \mathrm{ml}$ HIIIS. C: Lysis front movement was registered every $15 \mathrm{~min}$ by photoscanning the samples and measured $\mathrm{mm}$ values of $60 \mathrm{~min}$ lysis front (opaque clot/transparent fluid interface) movement were normalized for the distance of the two centres of orifices $(13 \mathrm{~mm})$ to give relative units (RU). Mean values and standard deviation of at least 7 measured values from 3 independent experiments are shown. Asterisk indicates a difference significant at $\mathrm{p}<0.05$ in comparison to control.

Fig. 4 Penetration of tissue plasminogen activator (tPA)-YFP into clots in the course of lysis. Clots were prepared from human plasma containing Alexa ${ }^{546}$-labeled fibrinogen, plasminogen and the indicated additives. After 30-min clotting tPA-YFP and plasminogen were added to the edge of the clot and the movement of the fluid/clot interface was monitored by confocal laser scanning microscopy using double fluorescent tracing (excitation $488 \mathrm{~nm} /$ emission $525 \mathrm{~nm}$ for tPA-YFP and excitation $543 \mathrm{~nm} / \mathrm{emission} 575 \mathrm{~nm}$ for fibrin). Images are shown for the $30 \mathrm{~min}$ after the application of tPA-YFP, scale bar $=50 \mu \mathrm{m}$. tPA-related fluorescence stains green, whereas the fibrin is red. At 0 time the edge of the clot was approximately at the top of each field of observation. The numbers indicate the relative distance for penetration of tPA-YFP in the clot at $30 \mathrm{~min}$ (all values are normalized by the mean value of clots with no additives): mean and standard deviation from at least 6 samples are shown. Asterisk indicates a difference significant at $p<0.05$ in comparison to control.

Fig. 5 tPA-induced lysis of clots containing DNA and HIIIS. Plasma clots containing plasminogen and the indicated additives were prepared in microplate wells, tPA was applied to the surface, and the absorbance was continuously measured at $340 \mathrm{~nm}$. A $A_{340}$ turbidity values were normalized $\left(\mathrm{nA}_{340}\right)$ as described in Materials and methods. Mean curves of 8 measurements from a representative experiment are shown. Dotted lines indicate source values of T0.5 and T0.1 parameters shown in the 
inset (time elapsed until 50\% and 90\% lysis, respectively). Inset: T0.5 and T0.1 values and standard deviation were calculated from mean values of 3 independent experiments with 6-8 replicas each. Asterisk indicates a difference significant at $\mathrm{p}<0.05$ test in comparison to control.

Fig. 6 Lysis of clots containing activated neutrophils. Plasma clots containing $5 \times 10^{3} / \mu 1$ granulocytes activated by PMA were prepared, $\mathrm{PPA} \pm$ the indicated additives were added to the surface and the absorbance was continuously measured at $340 \mathrm{~nm}$. $\mathrm{A}_{340}$ turbidity values were normalized as described in Materials and methods. Mean curves of 8 measurements from a representative experiment are shown. Concentrations of additives were: $200 \mathrm{nM}$ for tPA, $1 \mu \mathrm{M}$ for APC, $200 \mathrm{IU} / \mathrm{ml}$ for streptokinase (SK), $400 \mathrm{IU} / \mathrm{ml}$ for streptodornase (SD). Inset: macroscopic appearance of well contents after $200 \mathrm{~min}$ of lysis. Arrows point to web-like floating aggregates remaining after complete dissolution of the clots, the structure of which was further examined with SEM as illustrated by the inserted electronmicrograph (scale bar $=1 \mu \mathrm{m}$ ). 


\section{TABLES}

Table 1. Effect of DNA and histones on fibrin fiber diameter of plasma clots. SEM images of plasma clots containing the indicated additives and clotted with $16 / 60 \mathrm{nM}$ thrombin were used for the measurement of fiber diameter as previously described (18). The fiber size is reported in $\mathrm{nm}$ as median and bottom - top quartile values (in brackets) of the theoretical distributions fitted to the measured diameter values (4 SEM images per sample with 300 measured diameters in each). Asterisk indicates that the parameters of the fitted distributions differ from clots containing no additives at $p<0.05$. DNA was added at $50 \mu \mathrm{g} / \mathrm{ml}$, histone at $250 \mu \mathrm{g} / \mathrm{ml}$ concentration.

\begin{tabular}{|l|c|c|c|c|c|}
\hline \multicolumn{2}{|r|}{ Additive } & None & DNA & HIIIS & $\begin{array}{c}\text { DNA + } \\
\text { HIIIS }\end{array}$ \\
\hline $\begin{array}{l}\text { Fiber } \\
\text { diameter } \\
(\mathrm{nm})\end{array}$ & $16 \mathrm{nM}$ thrombin & $108(87-136)$ & $121(97-150)^{*}$ & $119(98-146)^{*}$ & $129(104-159)^{*}$ \\
\cline { 2 - 6 } & $60 \mathrm{nM}$ thrombin & $118(93-157)$ & $130(105-159)^{*}$ & $115(95-141)^{*}$ & $111(92-134)^{*}$ \\
\hline
\end{tabular}

Table 2. Permeability of clots containing DNA and histones. Clots were prepared from either $8 \mu \mathrm{M}$ fibrinogen or citrated plasma supplemented with $20 \mathrm{mM} \mathrm{CaCl}_{2}$ and the indicated additives and clotted with $16 \mathrm{nM}$ thrombin. The permeability coefficient (Ks) was calculated as described in Materials and methods. Ks values and standard deviation were calculated from at least 6 samples originating from 4 independent experiments. Asterisk indicates $\mathrm{p}<0.05$ in comparison with control containing no additives. DNA was added at $50 \mu \mathrm{g} / \mathrm{ml}$, histone at $250 \mu \mathrm{g} / \mathrm{ml}$ concentration.

\begin{tabular}{|l|l|l|l|l|l|}
\hline \multicolumn{2}{|r|}{ Additive } & \multicolumn{1}{c|}{ None } & DNA & HIIIS & \multicolumn{1}{c|}{$\begin{array}{c}\text { DNA }+ \\
\text { HIIIS }\end{array}$} \\
\hline \multirow{2}{*}{$\begin{array}{l}\text { Ks } \\
\left(10^{-9} \mathrm{~cm}^{2}\right)\end{array}$} & Fibrin & $0.62 \pm 0.13$ & $0.45 \pm 0.08^{*}$ & $2.43 \pm 0.81^{*}$ & $2.09 \pm 0.38^{*}$ \\
\cline { 2 - 7 } & Plasma & $6.43 \pm 2.58$ & $3.13 \pm 1.13^{*}$ & $3.68 \pm 0.91^{*}$ & $5.14 \pm 1.68$ \\
\hline
\end{tabular}

Table 3. Relative lysis times of clots containing activated neutrophils. Clots were prepared from 2fold diluted recalcified plasma isolated from the buffy coat fraction of human blood supplemented with $3.75 \mu \mathrm{M}$ plasminogen, and PMA-activated neutrophils at $5 \times 10^{3} / \mu 1$. After 4 hours of clotting initiated by $16 \mathrm{nM}$ thrombin, $200 \mathrm{nM}$ tPA \pm the indicated additives were applied to the surface of the clots, and lysis was followed by the continuous measurement of $\mathrm{A}_{340}$. Following evaluation of lysis progress curves, T0.5 and T0.1 values (time elapsed until 50\% and $10 \%$ lysis, respectively) were normalized as $\mathrm{T} 0.5 / \mathrm{T} 0.5_{\mathrm{T}}$ and $\mathrm{T} 0.1 / \mathrm{T} 0.1_{\mathrm{T}}$ for each of the experiments, where $\mathrm{T} 0.5_{\mathrm{T}}$ and $\mathrm{T} 0.1_{\mathrm{T}}$ represent the average values measured with tPA alone. Values are presented as mean \pm standard deviation calculated from 11-28 lysis curves originating from 3-5 independent experiments. Significant $(p<0.05)$ differences are indicated by $*$ for comparison with lysis in the absence of additives, by ${ }^{+}$for comparison with streptokinase and by ${ }^{\#}$ for comparison of the two different combinations of streptokinase + streptodornase.

\begin{tabular}{|l|l|l|l|l|l|l|}
\hline Additive & None & $\begin{array}{c}1 \mu \mathrm{M} \\
\text { APC }\end{array}$ & $\begin{array}{c}200 \mathrm{IU} / \mathrm{ml} \\
\text { streptokinase }\end{array}$ & $\begin{array}{c}200 \mathrm{IU} / \mathrm{ml} \\
\text { streptokinase } \\
+400 \mathrm{IU} / \mathrm{ml} \\
\text { streptodornase }\end{array}$ & $\begin{array}{c}500 \mathrm{IU} / \mathrm{ml} \\
\text { streptokinase }\end{array}$ & $\begin{array}{c}500 \mathrm{IU} / \mathrm{ml} \\
\text { streptokinase } \\
+1000 \mathrm{IU} / \mathrm{ml} \\
\text { streptodornase }\end{array}$ \\
\hline $\mathrm{T} 0.5$ & $1.00 \pm 0.10$ & $0.99 \pm 0.10$ & $0.89 \pm 0.11^{*}$ & $0.77 \pm 0.13^{*+}$ & $0.79 \pm 0.19^{*}$ & $0.57 \pm 0.12^{*+\#}$ \\
\hline $\mathrm{T} 0.1$ & $1.00 \pm 0.12$ & $0.96 \pm 0.08$ & $0.94 \pm 0.10$ & $0.89 \pm 0.13^{*}$ & $0.89 \pm 0.18$ & $0.83 \pm 0.12^{*}$ \\
\hline
\end{tabular}



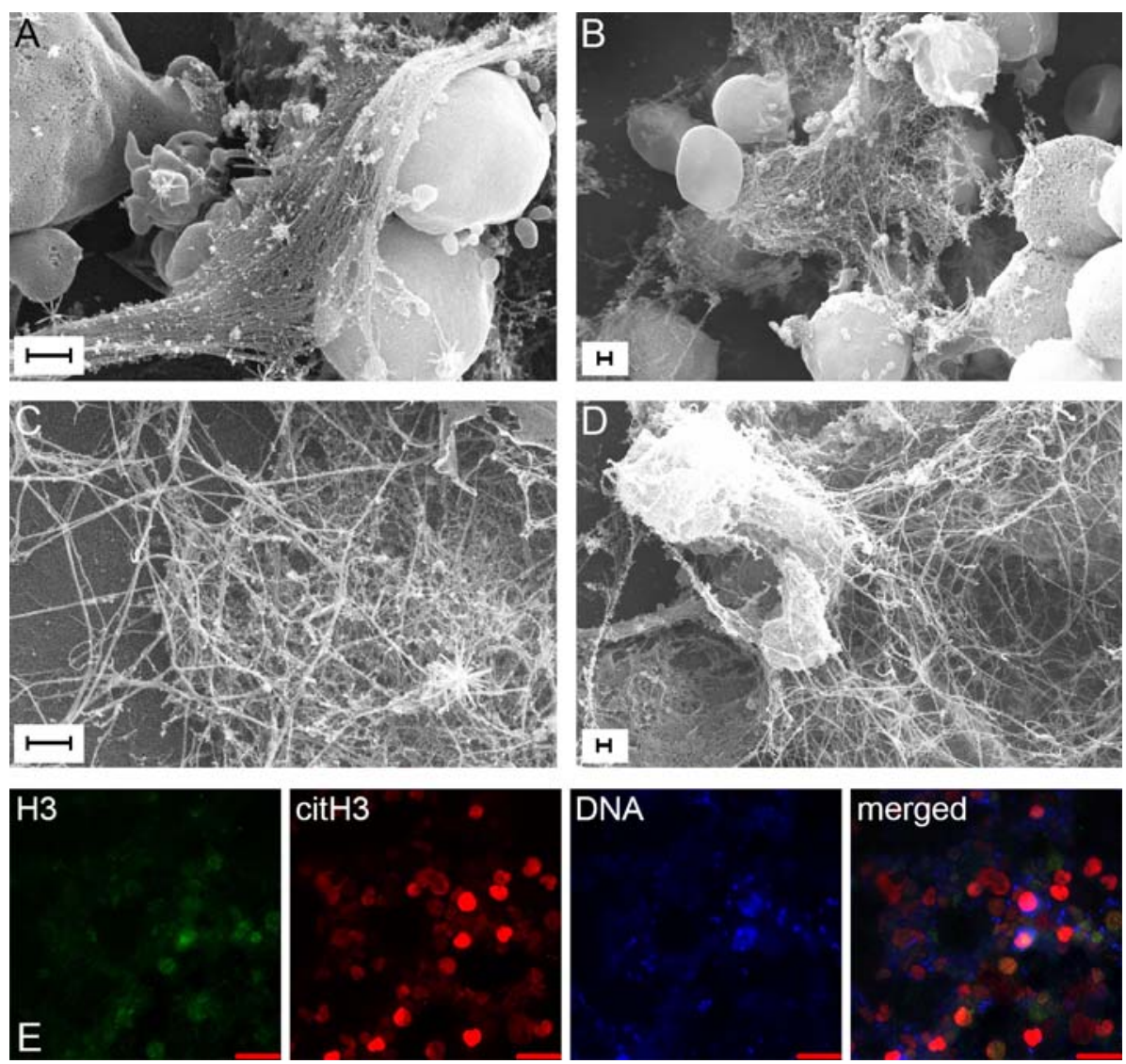

Figure 1 


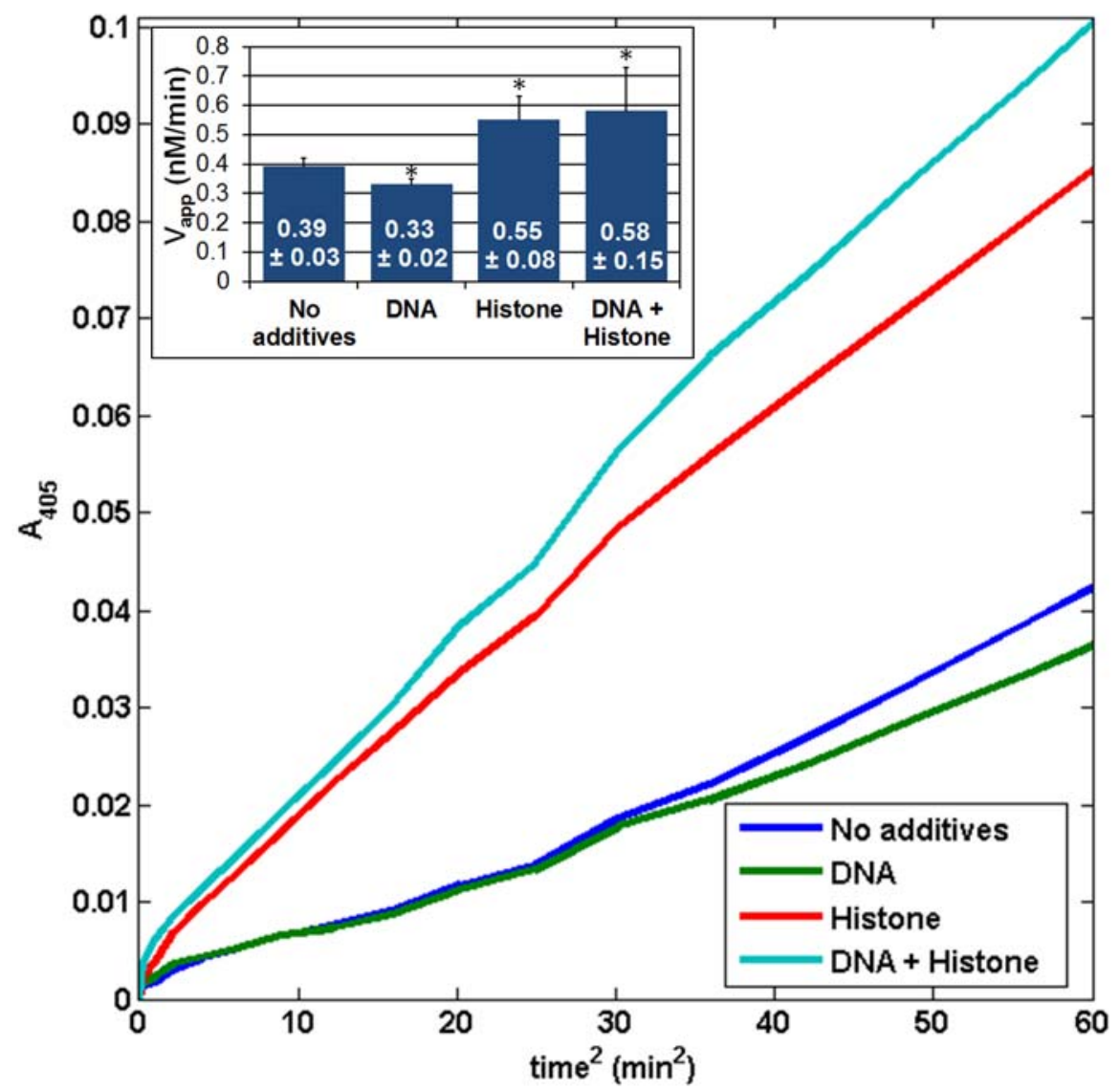

Figure 2 


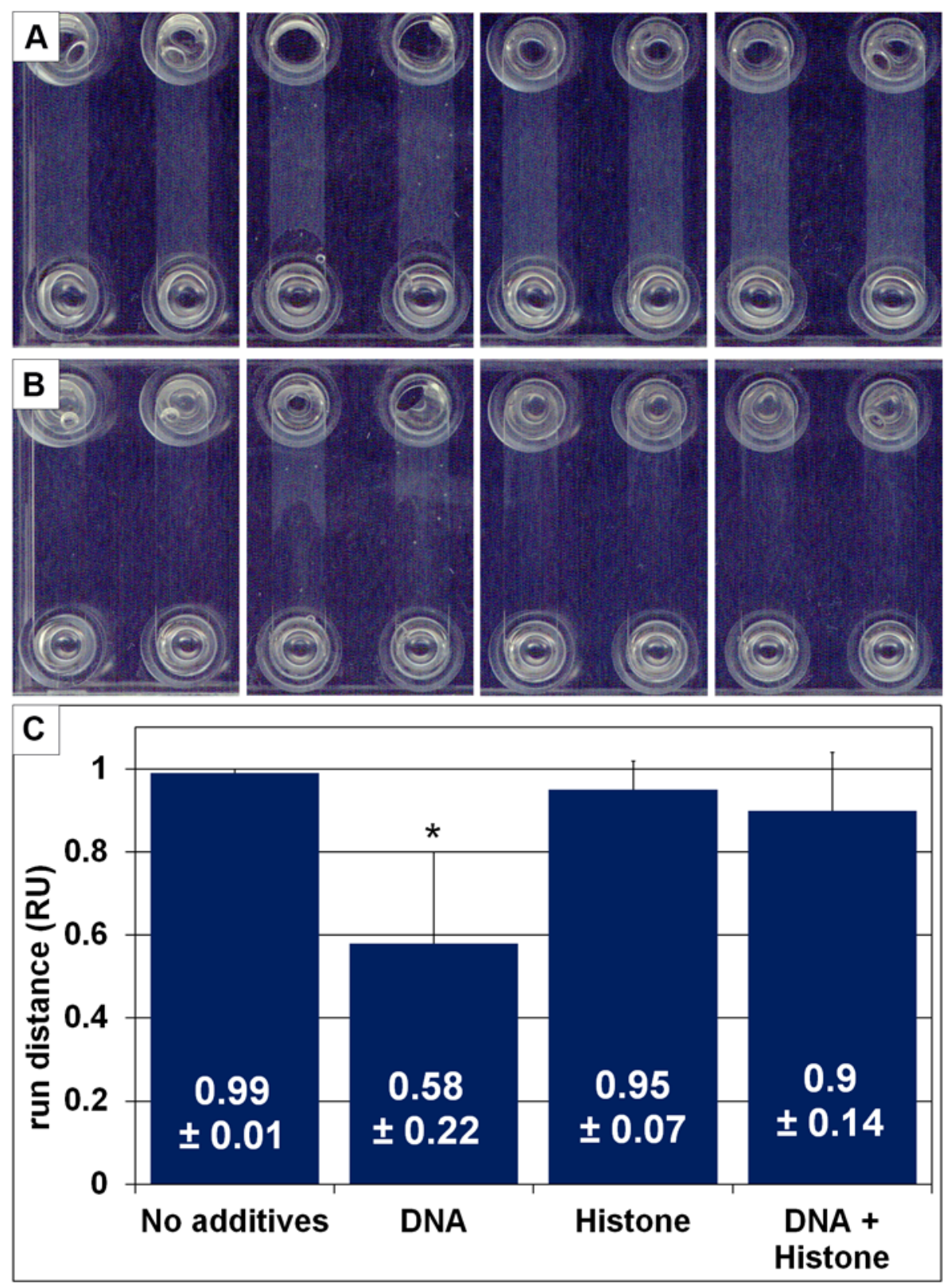

Figure 3 


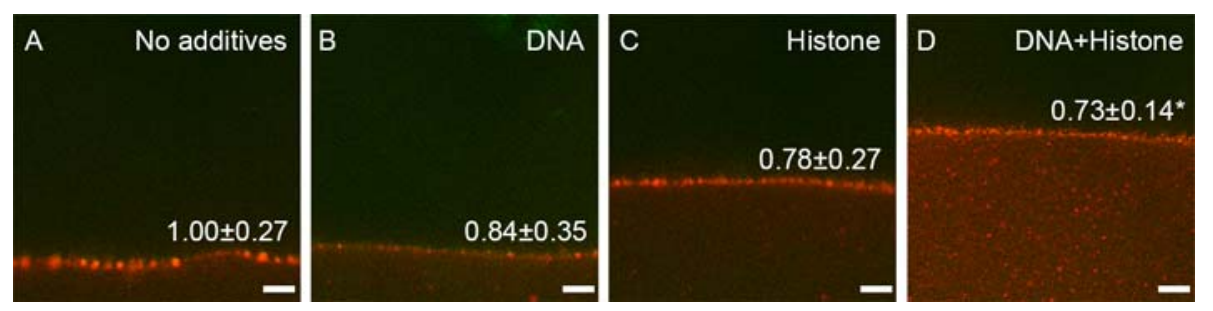

Figure 4 


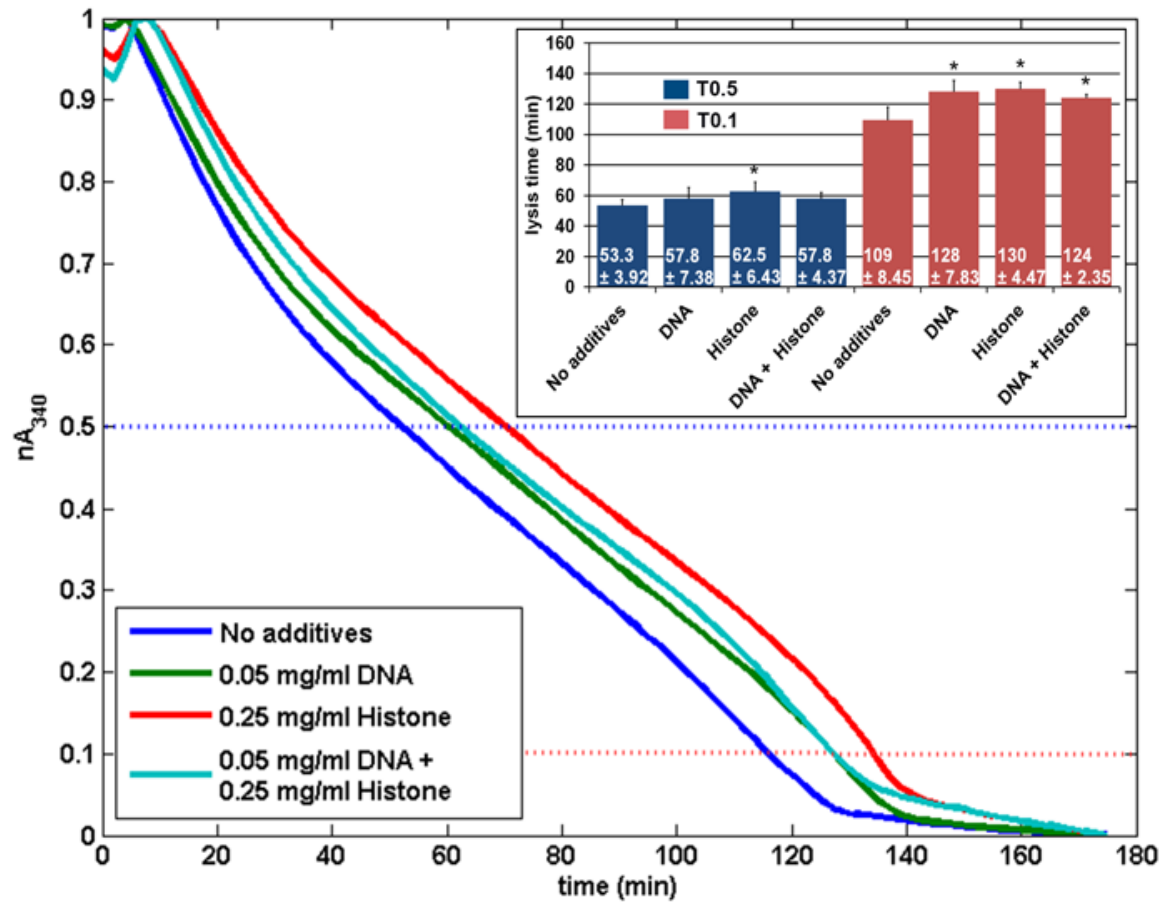

Figure 5 